\title{
Corneal stromal overgrowth after cataract extraction
}

\author{
ALAN H. FRIEDMAN AND PAUL HENKIND \\ From the Department of Ophthalmology, New York University School of Medicine
}

Corneal stromal overgrowth (retrocorneal membrane, fibrous overgrowth) is one of the common complications of penetrating keratoplasty (Kurz and D'Amico, 1968). As æo postoperative complication of cataract extraction leading to enucleation, however, it i⿱ less well recognized. Few case reports exist in the literature, and Duke-Elder (1969) failo to cite stromal overgrowth as a complication of cataract extraction. Two striking examples. of stromal overgrowth after cataract extraction will be reported: one after intracapsula and one after extracapsular surgery.

\section{Case reports}

Case 1, a 75-year-old female, had a cataract extracted from the left eye in April, 1969. A peri@ pheral iridectomy was performed and the lens was delivered intracapsularly. No note of vitreous loss or other complication was made at time of surgery. An iris prolapse with shallowing of the anterior chamber developed postoperatively. One week after the cataract extraction the patienథ had a sector iridectomy with reformation of the anterior chamber. She developed bullous kerato pathy and secondary glaucoma, and medical management was instituted without success. Cyclog diathermy was performed in August and again in September, 1969. The ocular tension was not controlled and the eye was enucleated in November, 1969 .

The specimen consisted of an intact, firm left eye measuring $24 \times 23.5 \times 24.5 \mathrm{~mm}$. with scand attached optic nerve. The cornea, which measured i I $\times$ I I mm., showed bullous keratopathy and its stroma was diffusely hazy. Superiorly a retrocorneal membrane was present. A secto iridectomy and inferior sphincterotomy was seen. The globe was opened in the vertical meridiang and the lens was absent. Peripheral anterior synechiae occluded the anterior chamber angle Focal areas of depigmentation surrounded by hyperpigmentation were present in the pars plan@ inferiorly.

\section{MICROSGOPIGAL EXAMINATION}

The subconjunctival tissue shows a mild, round cell infiltration. The corneal epithelium is thinne年 focally, but is intact. Several large epithelial bullae are present. Bowman's membrane hass scattered defects. A fibrovascular membrane, most marked near the limbus, lies between the basement membrane of the epithelium and Bowman's membrane. A vascularized surgical scar extends from behind the limbus, continues almost parallel to the plane of the cornea, and enters the anterior chamber anterior to Schwalbe's line (Fig. I). Uveal pigment is present within the vascularized scar. The remainder of the stroma shows deep vascularization and round cell infiltration Descemet's membrane is thickened, irregular, and broadly interrupted at the inner aspect of the scarop

Through this interruption a large stromal overgrowth or retrocorneal membrane is present (Fig. 2 ) 




(a)

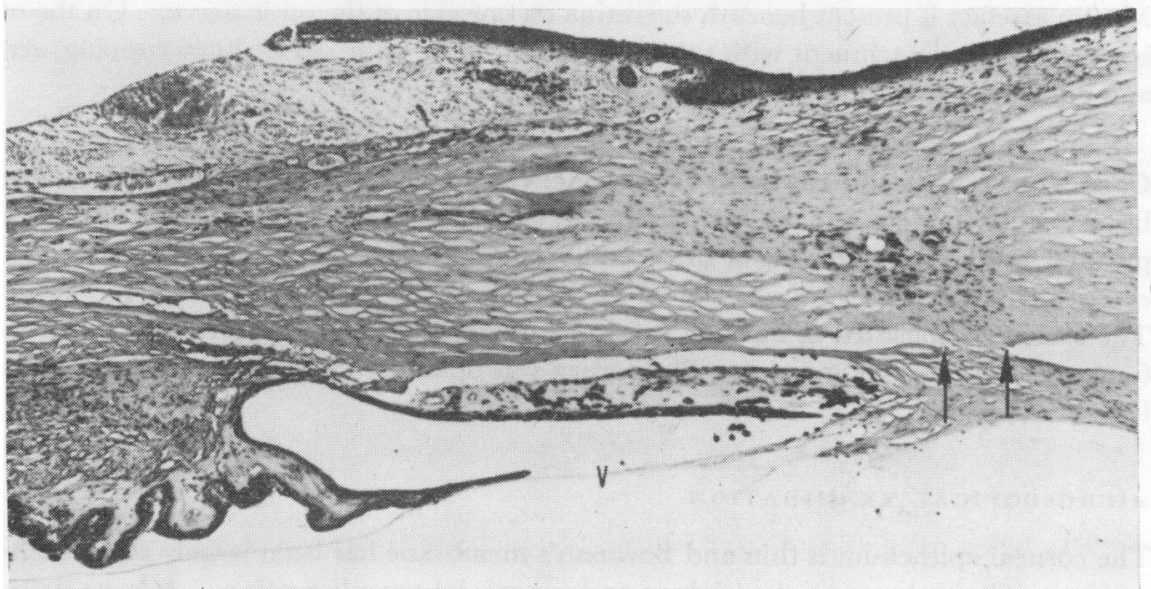

(b)

FIG. I Case I

(A) Low-power photomicrograph, showing stromal overgrowth (SO), vitreous $(V)$, and subepithelial bulla (B). Track of surgical incision delineated by arrow. Haematoxylin and eosin. $\quad \times 15$

(B) Higher-power view of stromal overgrowth, showing dehiscence in Descemet's membrane (between arrows) and a vitreous strand $(V) . \quad$ Haematoxylin and eosin. $\times 30$

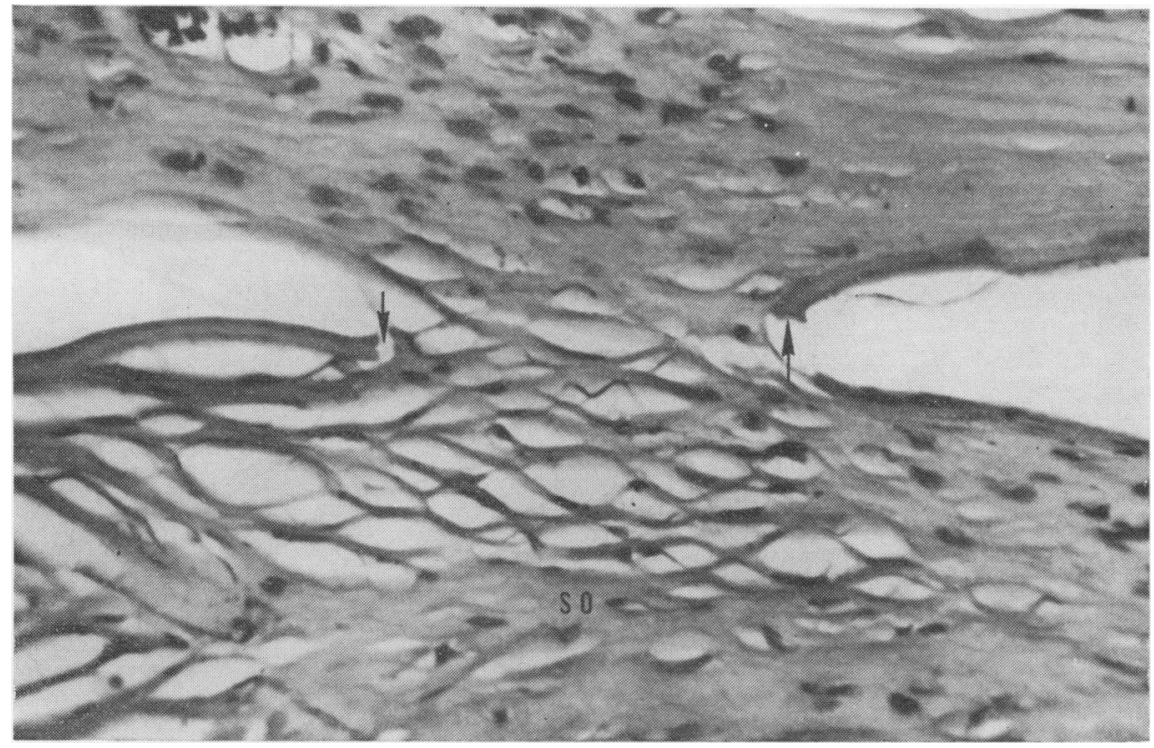

FIG. 2 Case I. High-power view of dehiscence in Descemet's membrane (between arrows) and stromal overgrowth $(S O)$. Cornea with iris pigment is seen above. Haematoxylin and eosin. $\times 240$ 
It attaches, on one side, to the remnant of iris and to the vitreous (Fig. I). This overgrowth continues toward the opposite limbus along the cornea, from which it is artificially separated. The anterior chamber angle is closed by peripheral anterior synechiae. Hyalinization of the sphincter muscle and degeneration of the dilator muscle are present in the iris. Ciliary processes are hyalinized. On the side with the iridectomy the most anterior ciliary process is pulled towards the wound by a vascularized strand. The retina shows peripheral cystoid degeneration. In the periphery on the inferior side chorio-retinal adhesions are present. Here the retina is degenerated; the retinal pigment epithelium is absent; focal pigment clumps are present; and the cortical vitreous is applied to the internal limiting membrane. Ganglion cells are absent and the nerve fibre layer is degenerated. Myelin artefact is present beneath the retina on one side of the optic nerve. On the other side there $\vec{D}$ is a flat retinal detachment with subretinal fluid. The optic nerve shows cupping, atrophy of fibres, and glial proliferation. The vitreous is collapsed.

Case 2, a 60-year-old male, had a cataract extraction of the right eye in November, 1967. The history is incomplete but the extraction was extracapsular, and the postoperative course was complicated by the development of intractable secondary glaucoma; 9 months later the blind painful eye was enucleated.

The specimen consisted of an intact, firm, shrunken right eye measuring $22 \times 20 \times 20 \mathrm{~mm}$. with $\stackrel{?}{3}$ $6 \mathrm{~mm}$. of attached optic nerve. The cornea was opaque. The globe was opened vertically. The lens was absent.

\section{MICROSCOPICAL EXAMINATION}

The corneal epithelium is thin and Bowman's membrane has been largely replaced by degenerative pannus. Corneal stroma shows deep and superficial vascularization. A large defect is present in Descemet's membrane near the limbus (Fig. 3). Through the defect a large stromal overgrowth has developed (Fig. 4). The fibrous tissue fills the angle on this side, extends along the posterior surface of the cornea, and is present in the opposite angle. Descemet's membrane is reduplicated near the dehiscence. Peripheral anterior synechiae occlude the angle. The iris stump, angle structures, and ciliary body are infiltrated by chronic inflammatory cells. Fragments of lens capsule and sub-



FIG. 3 Case 2. Low-power view, showing corneal cicatrix $(C)$, dehiscence in Descemet's membrane (between arrows), and stromal overgrowth $(\mathrm{SO})$. Haematoxylin and eosin. $\times 3^{0}$ 


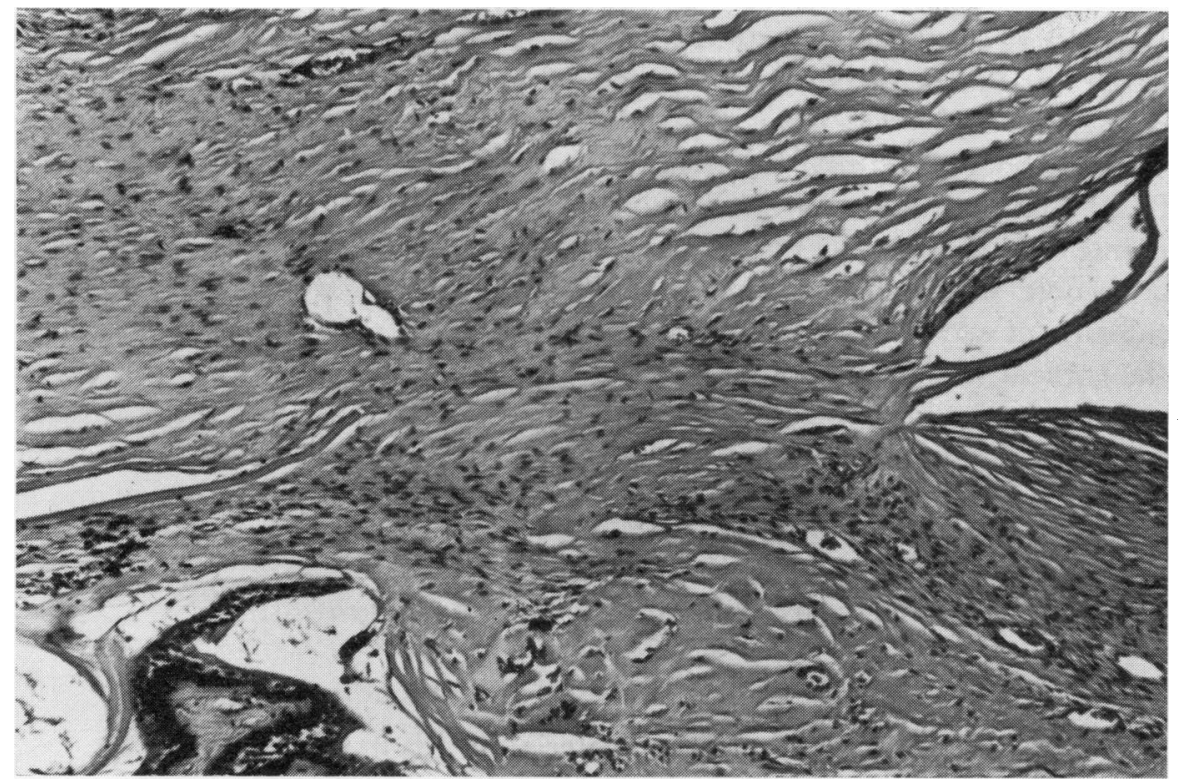

FIG. 4 Case 2. Higher-power view, showing defect and stromal overgrowth. Ciliary processes are seen on the left. Haematoxylin and eosin. $\quad \times 75$

capsular epithelium lie in the pupil and are applied to the retrocorneal membrane. A vascularized cyclitic membrane incorporates the vitreous and the totally detached retina. Posteriorly a serous exudate lies beneath the retina. The optic nerve is atrophic and myelin extrusion is present in the nerve head.

\section{Comment}

Normal corneal wound healing after cataract extraction follows a definite pattern (Dunnington, 1956). Primary closure of the corneal incision is due to swelling of the corneal lamellae, mostly as a result of imbibition of aqueous. Within 3 or 4 days fibroblastic proliferation commences and stromal healing begins. Early in the reparative phase the anterior and posterior edges of the wound retract. The epithelial integrity is restored by a slide from the wound edges and by proliferation. During this period epithelium may extend along and under the incisional tract. The anterior triangle of epithelium is gradually expelled by the proliferation of fibroblasts. Descemet's membrane is retractile and will form folds and scrolls. The posterior wound gape is repaired later after stromal proliferation is well established. Endothelium proliferates and bridges the defect.

Henderson (1907, 1914), studying Fuchs's cases of faulty wound apposition, noted proliferation of connective tissue into the anterior chamber. He thought this to be due to the presence of incarcerated iris, lens debris, or lens capsule within the wound acting as a bridge and allowing subconjunctival tissue entry into the anterior chamber. A fibrotic mass could then form in the angle and upper part of the anterior chamber leading to closure of the filtration angle with secondary glaucoma. Collins (1914) did not accept Henderson's thesis and suggested that proliferation of connective tissue was not possible without the presence of infective material. Swan (195I) attributed the fibroplasia to scleral reaction in the presence of lens matter, fibrin, or vitreous incarcerated in the wound. 
Levkoieva (1947) and Duke-Elder (1954) described corneal stromal overgrowth as brought


connective tissue was histologically identical to and arises from corneal stroma. Both these authors stated that the irritating influence of incarcerated ocular tissue and ocular fluids was necessary for the production of stromal overgrowth. Christensen (1965)흠 pointed out that contact between intraocular structures and wound surfaces might provoke $\frac{\overline{\bar{p}}}{7}$ a chronic inflammatory reaction. This produced a prolonged reparative phase and $\stackrel{\Phi}{\Omega}$ subsequent excessive intraocular fibrocytic reaction. Formed vitreous being irritating in the corneal wound, its presence would promote fibroplasia. In this regard Blodi (1965) $\vec{\circ}$

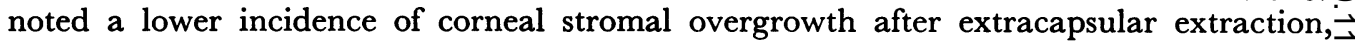
in which, presumably, the vitreous face was not in contact with the wound. Also the presence of vitreous within the wound would provide a bridge for entry into and prolifera $-\frac{0}{0}$. tion within the eye of a fibrocytic membrane.

Thus three elements are necessary for stromal overgrowth:

(1) Posterior gaping or over-riding of the wound;

(2) Incarceration of vitreous, lens material, or iris in the wound;

(3) Inflammation within the eye.

In a case reported by Wood (1932), the stromal overgrowth was associated with marked $\overrightarrow{0}$ iridocyclitis. In our cases contributory factors in the production of stromal overgrowth were:

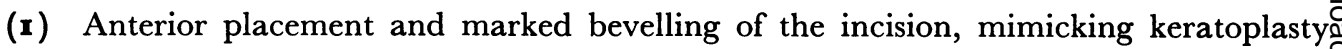
(Case I);

(2) Postoperative iris prolapse and flat chamber which permitted posterior gaping of the wound for at least I week (Case I);

(3) Iris incarceration in the wound (Cases I and 2);

(4) Vitreous incarceration in the wound as evidenced by adhesion between the vitreous:face and the retrocorneal membrane (Cases I and 2);

(5) Postoperative inflammation (Cases $I$ and 2).

Leading ophthalmic pathology textbooks (Hogan and Zimmerman, I 962; von Hippel,, 1928; Parsons, 1904) do not mention corneal stromal overgrowth as a complication ofo cataract extraction. Duke-Elder, in an earlier work (1954), discussed stromal overgrowth following trauma; he cited the case of Wood (1932) as following cataract extraction, but did not include it in a long list of cataract complications in his more recent work (1969). N Treatises on cataract surgery and its complications (for example, Kirby, 1950; McDonald, 1965; Stallard, 1965; de St Martin, i935) also fail to list corneal stromal overgrowth. In six reported series, eyes enucleated after cataract extraction were studied histologically. These results are summarized in the Table (opposite).

Payne, Simonton, and Cury (1955) reviewed 333 and Schulze and Duke (1965) roo궁 globes removed after cataract extraction and did not mention corneal stromal overgrowth as a cause for enucleation. Blodi (1965) noted 25I eyes enucleated after cataract extrac-命 tion; stromal overgrowth was responsible for five cases, four after intracapsular and one 
Table Corneal stromal overgrowth in eyes enucleated after cataract extraction

\begin{tabular}{|c|c|c|c|c|}
\hline Author & Date & $\begin{array}{l}\text { No. } \\
\text { of } \\
\text { eyes }\end{array}$ & $\begin{array}{l}\text { Corneal } \\
\text { stromal } \\
\text { overgrowth }\end{array}$ & $\begin{array}{l}\text { Epithelial } \\
\text { downgrowth }\end{array}$ \\
\hline Payne and others & 1955 & 333 & o & 60 \\
\hline Dunnington & 1955 & 171 & $5^{6}$ & 62 \\
\hline Blodi & 1965 & $25^{I}$ & 5 & 63 \\
\hline Schulze and Duke & 1965 & 100 & o & 17 \\
\hline Allen & 1968 & 50 & I 8 & 13 \\
\hline Bettman & 1969 & 74 & 25 & 5 \\
\hline
\end{tabular}

after extracapsular extraction. Dunnington (1956) noted that, of 297 globes removed after cataract extraction between 1929 and I954, I 7 I were due to faulty wound healing, and stromal proliferation was responsible for $5^{6}$ of these. No mention was made of the ratio of intracapsular to extracapsular extractions. The enucleation often followed loss of vitreous and incarceration of tissue in the wound, and large amounts of lens cortex and capsule were frequently found adjacent to the wound. Allen (1968) studied stromal and epithelial ingrowths in fifty eyes removed after cataract extraction, stromal overgrowth was found in eighteen and epithelial downgrowth in thirteen. Bettman (1969) studied 74 eyes removed after cataract extraction; stromal overgrowth was found in 21 of 61 eyes removed after intracapsular extraction and in four of thirteen removed after extracapsular extraction. Bettman noted the frequent association of a stripped Descemet's membrane with stromal overgrowth.

The clinical recognition of corneal stromal overgrowth and its differentiation from epithelial downgrowth has been discussed by Swan (I95I). The features of an epithelial downgrowth are an irregularly scalloped border, semitransparency, and a smooth regular surface. If unchecked, the epithelium will grow down along the corneal endothelium into the angle, and over the iris, ciliary body, and vitreous. Stromal overgrowths characteristically develop in areas where endothelium has been injured and Descemet's membrane stripped or gaping. The fibrous tissue will grow on the surface or invade the vitreous. The appearance of stroma differs from epithelium. Fibrous tissue is grey or white and Swan likened the appearance of the interlacing meshwork of fibres to that of woven cloth. In addition, the edges of the stromal overgrowth are frayed because of the penetration ahead of the fibroblastic strands. Considering that a stromal overgrowth is composed of actively developing fibroblastic tissue, radiation therapy may be helpful in arresting its development, and surgical intervention may be necessary.

\section{Summary}

Two examples are reported of corneal stromal overgrowth after cataract extraction. In one case the overgrowth followed intracapsular and in the other extracapsular extraction. The mechanism of its development and its clinical recognition are discussed. Previous studies noting the incidence of corneal stromal overgrowth after cataract extraction are summarized.

We wish to thank Mrs. Doris Ortega for secretarial work and Mr. Henrick Malpica for the illustrations. 


\section{References}

Allen, J. c. (1968) Amer. F. Ophthal., 65, I 79

BetTMAN, J. (1969) Ibid., 68, 1037

BLODI, F. C. (1965) Int. Ophthal. Clin., 5, 257

Christensen, L. (1965) In "Symposium on Cataracts", Trans. New Orleans Acad. Ophthal., p. I96.

Mosby, St. Louis

COLlins, E. TREACHER (1914) Trans. ophthal. Soc. U.K., 34, 94

DUKE-ELDER, s. (1954) "Textbook of Ophthalmology", vol. 6, p. 6or 2. Kimpton, London

(1969) "System of Ophthalmology", vol. 1 1, p. 277. Kimpton, London

dunnington, J. H. (1956) A.M.A. Arch. Ophthal., 56, 639

HENDERSON, T. (1907) Ophthal. Rev., 26, 127

- (1914) Trans. ophthal. Soc. U.K., 34, 88

HIPPEL, E. VON (1928) In "Handbuch der speziellen pathologischen Anatomie und Histologie",

ed. F. Henke and O. Lubarsch, band i "Auge", teil I, p. 261. Springer, Berlin

hogan, M. J., and zimmerman, L. E. (1962) "Ophthalmic Pathology", 2nd ed. Saunders,

Philadelphia

KIRBY, D. B. (1950) "Surgery of Cataract", p. 488. Lippincott, Philadelphia

KURZ, G. H., and D'AMICo, R. A. (1968) Amer. F. Ophthal., 66, 184

LEVkoleva, E. TH. (1947) Brit. F. Ophthal., 31, 336

MACDONALD, P. R. (1965) In "Complications in Eye Surgery", 2nd ed., ed. R. M. Fasanella, p. 209.

Saunders, Philadelphia

PARsons, J. H. (1904) "The Pathology of the Eye", vol. I, p. 165. Hodder and Stoughton, London PAYNe, B. F., SImONTON, J. T., and CURY, D. (1955) Trans. Amer. ophthal. Soc., 53, 231

SAINT MARTIN, R. DE (1935) "L'extraction capsulo-lenticulaire de la cataracte", p. I94. Masson,

Paris

SCHULZE, R. D., and DUKE, J. R. (1965) Arch. Ophthal. (Chicago), 73, 74

STALlaRd, H. B. (1965) "Eye Surgery", 4th ed., p. 5 18. Wright, Bristol

sWAN, K. G. (1951) A.M.A. Arch. Ophthal., 45, 630

wood, D. J. (1932) Brit. F. Ophthal., 16, 546 